\title{
Inquérito sorológico da infecção por herpesvírus equino no Estado de Minas Gerais
}

\author{
Serological survey of equine herpesvirus infection in Minas Gerais state
}

\section{Maria do Carmo Custódio de Souza Hunold LARA ${ }^{1}$; Camila Souza TORELLI ${ }^{2}$; Elenice Maria Sequetin CUNHA $^{1}$; Eliana Monteforte Cassaro VILLALOBOS ${ }^{1}$; Mariana Sequetin CUNHA ${ }^{1}$; Ana Cristina P. P. BELLO $^{3}$; Arildo P. CUNHA ${ }^{3}$; Jenner K. P. REIS ${ }^{3}$; Rômulo Cerqueira LEITE; Enio MORI ${ }^{2}$}

\author{
${ }^{1}$ Instituto Biológico, São Paulo - SP \\ ${ }^{2}$ Faculdade de Medicina Veterinária e Zootecnia da Universidade de São Paulo, São Paulo - SP \\ ${ }^{3}$ Escola de Veterinária da Universidade Federal de Minas Gerais, Belo Horizonte - MG
}

\begin{abstract}
Resumo
Os herpesvírus equinos tipo 1 (HVE-1) e 4 (HVE-4) são agentes causadores de diferentes formas de doença em cavalos, das quais as mais comuns são a rinopneumonite, o abortamento, a mortalidade perinatal e a mieloencefalopatia herpética equinas, que causam grandes perdas econômicas. Tem sido descrita mundialmente, havendo poucos estudos no Brasil. O objetivo do presente trabalho foi estudar a ocorrência e a distribuição da infecção por herpesvírus equinos (HVE) em equídeos criados em dez Delegacias Regionais do Estado de Minas Gerais: Almenara, Bambuí, Curvelo, Governador Valadares, Montes Claros, Oliveira, São Gonçalo do Sapucaí, Teófilo Otoni, Unaí e Viçosa. Foi utilizada a técnica de soroneutralização em microplacas com o intuito de detectar anticorpos soro neutralizantes. Das amostras analisadas, $17,6 \%$ (145/826) foram soropositivas para o HVE, sendo 18,7\% (140/749) cavalos soropositivos, 6,8\% (5/73) muares soropositivos e nenhum asinino soropositivo (0/4). Conclui-se que o HVE-1 encontra-se amplamente disseminado no Estado de Minas Gerais, pois todas as regiões estudadas apresentaram animais sororreagentes ao HVE-1. Observou-se maior ocorrência de anticorpos contra o HVE em animais adultos, indicando assim o potencial desses animais como fonte de infecção para os potros.
\end{abstract}

Palavras-chave: Equídeos. Estado de Minas Gerais. Herpesvírus equino. HVE.

\begin{abstract}
Equine herpesvirus type $1(\mathrm{EHV}-1)$ and $4(\mathrm{EHV}-4)$ are major pathogens affecting horses, and cause respiratory disease, abortion, perinatal mortality and neurological disease, bringing economical losses. This infection has been reported worldwide, but there are only a few studies in Brazil. The present study was undertaken in order to evaluate the occurrence and distribution of equine herpesviruses (EHV) infection in equids from ten regions of Minas Gerais State: Almenara, Bambuí, Curvelo, Governador Valadares, Montes Claros, Oliveira, São Gonçalo do Sapucaí, Teófilo Otoni, Unaí and Viçosa. To detect antibodies against EHV virus neutralization test in microplates was used. We found $17.6 \%$ $(145 / 826)$ positive animals for EHV. $18.7 \%$ (140/749) positive horses, 6.8\% (5/73) positive mules and none positive (0/4) donkeys. All ten regions studied showed animals reagents to EHV. The results suggest that EHV is widespread in equids of Minas Gerais State. It was observed a higher occurrence of antibodies against EHV in adult animals, indicating the potential of these animals as source of infection for foals.
\end{abstract}

Keywords: Equids. Minas Gerais State. Equine herpesvirus. EHV.

\section{Introdução}

Os herpesvírus equinos tipos 1 (HVE-1) e 4 (HVE4) são DNA vírus pertencentes à família Herpesviridae, subfamília Alphaherpesvirinae e gênero Varicellovirus. Ambos os vírus apresentam distribuição mundial e são agentes infecciosos importantes para a espécie equina, causando diferentes formas de doença, sendo a rinopneumonite, o abortamento a vírus, a mortalidade perinatal e a mieloencefalopatia as mais frequentes $^{1,2}$.
Sabe-se que os herpesvírus equinos (HVE) encontram-se amplamente disseminados na população equina em todo o território nacional. Diversos isola-

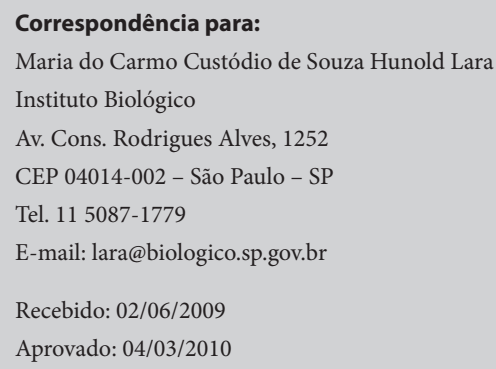


dos originários de casos de doença neurológica ${ }^{3}$ e de abortamento ou mortalidade perinatal ${ }^{4,5,6,7,8}$ já foram estudados. No entanto, a ocorrência dessa infecção viral herpética em equídeos criados no Estado de Minas Gerais não foi suficientemente investigada, não tendo sido realizados até o presente momento, estudos soroepidemiológicos referentes a infecções causadas pelos HVE nesse Estado.

Devido a isso, este presente trabalho teve como objetivo verificar a frequência e a distribuição de anticorpos anti-HVE em equídeos criados no Estado de Minas Gerais.

\section{Material e Método}

Foram colhidas 826 amostras de soro sanguíneo de equídeos pertencentes a dez Delegacias Regionais do Estado de Minas Gerais, no ano de 2002, distribuídas de acordo com a tabela 1 . As amostras de sangue foram obtidas assepticamente por punção da veia jugular externa e os soros obtidos após retração do coágulo e estocados $\mathrm{a}-20^{\circ} \mathrm{C}$ até a realização das provas laboratoriais. As amostras de sangue obtidas foram divididas de acordo com a espécie animal, sexo e idade (Tabelas 2 e 3 ).

A detecção de anticorpos contra os HVE foi realizada pela técnica de soroneutralização em microplacas, segundo metodologia descrita por Kotait et al. ${ }^{9}$. A amostra viral padrão utilizada foi a A4/72 4 mantida no Instituto Biológico de São Paulo em células VERO. Os títulos dos soros sanguíneos (expressos em $\log _{10}$ ) foram considerados positivos a partir da menor diluição (maior ou igual a 4) capaz de inibir 100\% do efeito citopático (ECP).

\section{Resultados}

O presente estudo pesquisou pela primeira vez a presença de anticorpos contra HVE em equídeos criados no Estado de Minas Gerais. Das amostras analisadas $17,6 \%$ (145/826) foram soropositivas para esse agente, sendo $18,7 \%(140 / 749)$ cavalos soropositivos, 6,8\% (5/73) muares soropositivos e nenhum asinino soropositivo (0/4) (Tabela 1$)$.

Tabela 1 - Ocorrência da infecção por herpesvírus equino determinada pela reação de soroneutralização em microplacas, em soro sanguíneo de equídeos criados no Estado de Minas Gerais, agrupados segundo a procedência das amostras e espécie animal - Belo Horizonte - 2002

\begin{tabular}{|c|c|c|c|c|c|c|c|c|}
\hline \multirow[b]{2}{*}{ Delegacias Regionais } & \multicolumn{4}{|c|}{ No Animais } & \multicolumn{4}{|c|}{ Reagentes } \\
\hline & Total & $\begin{array}{c}\text { Equino } \\
(\%)\end{array}$ & $\begin{array}{c}\text { Asinino } \\
(\%)\end{array}$ & $\begin{array}{c}\text { Muar } \\
(\%)\end{array}$ & Total & $\begin{array}{c}\text { Equino } \\
(\%)\end{array}$ & $\begin{array}{c}\text { Asinino } \\
(\%)\end{array}$ & $\begin{array}{c}\text { Muar } \\
(\%)\end{array}$ \\
\hline Almenara & 130 & $\begin{array}{c}118 \\
(15,71)\end{array}$ & $\begin{array}{c}1 \\
(25)\end{array}$ & $\begin{array}{c}11 \\
(15,07)\end{array}$ & 24 & $\begin{array}{c}24 \\
(17,3)\end{array}$ & 0 & 0 \\
\hline Bambuí & 44 & $\begin{array}{c}37 \\
(4,93)\end{array}$ & $\begin{array}{c}1 \\
(25)\end{array}$ & $\begin{array}{c}6 \\
(8,22)\end{array}$ & 8 & $\begin{array}{c}8 \\
(5,7)\end{array}$ & 0 & 0 \\
\hline Curvelo & 88 & $\begin{array}{c}78 \\
(10,41)\end{array}$ & 0 & $\begin{array}{c}10 \\
(13,70)\end{array}$ & 14 & $\begin{array}{c}13 \\
(9,3)\end{array}$ & 0 & $\begin{array}{c}1 \\
(20)\end{array}$ \\
\hline Gov. Valadares & 47 & $\begin{array}{c}44 \\
(5,86)\end{array}$ & $\begin{array}{c}1 \\
(25)\end{array}$ & $\begin{array}{c}2 \\
(2,74)\end{array}$ & 1 & $\begin{array}{c}1 \\
(0,7)\end{array}$ & 0 & 0 \\
\hline Montes Claros & 92 & $\begin{array}{c}81 \\
(10,78)\end{array}$ & 0 & $\begin{array}{c}11 \\
(15,07)\end{array}$ & 9 & $\begin{array}{c}8 \\
(5,7)\end{array}$ & 0 & $\begin{array}{c}1 \\
(20)\end{array}$ \\
\hline Oliveira & 47 & $\begin{array}{c}46 \\
(6,14)\end{array}$ & $\begin{array}{c}1 \\
(25)\end{array}$ & 0 & 9 & $\begin{array}{c}9 \\
(6,4)\end{array}$ & 0 & 0 \\
\hline S. G. do Sapucaí & 45 & $\begin{array}{c}45 \\
(5,99)\end{array}$ & 0 & 0 & 12 & $\begin{array}{c}12 \\
(8,6)\end{array}$ & 0 & 0 \\
\hline Teófilo Otoni & 147 & $\begin{array}{c}133 \\
(17,71)\end{array}$ & 0 & $\begin{array}{c}14 \\
(19,18)\end{array}$ & 25 & $\begin{array}{c}25 \\
(17,9)\end{array}$ & 0 & 0 \\
\hline Unaí & 128 & $\begin{array}{c}113 \\
(15,04)\end{array}$ & 0 & $\begin{array}{c}15 \\
(20,55)\end{array}$ & 28 & $\begin{array}{c}25 \\
(17,9)\end{array}$ & 0 & $\begin{array}{c}3 \\
(60)\end{array}$ \\
\hline Viçosa & 58 & $\begin{array}{c}54 \\
(7,19) \\
\end{array}$ & 0 & $\begin{array}{c}4 \\
(5,48) \\
\end{array}$ & 15 & $\begin{array}{c}15 \\
(10,7) \\
\end{array}$ & 0 & 0 \\
\hline Total & 826 & $\begin{array}{c}749 \\
(100)\end{array}$ & $\begin{array}{c}4 \\
(100)\end{array}$ & $\begin{array}{c}73 \\
(100)\end{array}$ & 145 & $\begin{array}{c}140 \\
(100)\end{array}$ & 0 & $\begin{array}{c}5 \\
(100)\end{array}$ \\
\hline
\end{tabular}


Tabela 2 - Resultados obtidos pela técnica de soroneutralização em microplacas, para detecção de anticorpos anti-HVE, em amostras de soro sanguíneo de equídeos criados no Estado de Minas Gerais, distribuídos segundo o sexo - Belo Horizonte - 2002

\begin{tabular}{lcccc}
\hline & \multicolumn{4}{c}{ Sexo } \\
\cline { 2 - 5 } Espécie & \multicolumn{3}{c}{ Macho (\%) } & Fêmea (\%) \\
\cline { 2 - 5 } & $\begin{array}{c}\mathrm{N} \\
(\%)\end{array}$ & Reagentes (\%) & $\begin{array}{c}\mathrm{N} \\
(\%)\end{array}$ & Reagentes (\%) \\
\hline \multirow{2}{*}{ Equina } & 543 & 104 & 206 & 36 \\
& $(72,5)$ & $(74,3)$ & $(27,5)$ & $(25,7)$ \\
Muar & 40 & 3 & 33 & 2 \\
& $(54,8)$ & $(60,0)$ & $(45,2)$ & $(40,0)$ \\
Asinina & 4 & - & - & - \\
& $(100)$ & $(0)$ & $(0)$ & $(0)$ \\
\hline \multirow{2}{*}{ Total } & 587 & 107 & 239 & 38 \\
& $(71,1)$ & $(73,8)$ & $(28,9)$ & $(26,2)$ \\
\hline
\end{tabular}

Tabela 3 - Resultados obtidos pela técnica de soroneutralização em microplacas, para detecção de anticorpos anti-HVE, em amostras de soro sanguíneo de equídeos criados no Estado de Minas Gerais, distribuídos segundo a espécie e faixa etária - Belo Horizonte - 2002

\begin{tabular}{|c|c|c|c|c|c|c|}
\hline \multirow{3}{*}{ Espécie } & \multicolumn{6}{|c|}{ Idade } \\
\hline & \multicolumn{2}{|c|}{$<1$ ano (\%) } & \multicolumn{2}{|c|}{1 a 4 anos (\%) } & \multicolumn{2}{|c|}{$>4$ anos $(\%)$} \\
\hline & $\begin{array}{c}\mathrm{N} \\
(\%)\end{array}$ & Reagentes (\%) & $\begin{array}{c}\mathrm{N} \\
(\%)\end{array}$ & Reagentes (\%) & $\begin{array}{c}\mathrm{N} \\
(\%)\end{array}$ & Reagentes (\%) \\
\hline Equina & $\begin{array}{c}2 \\
(0,27)\end{array}$ & $\begin{array}{c}- \\
(0)\end{array}$ & $\begin{array}{c}202 \\
(26,97)\end{array}$ & $\begin{array}{c}32 \\
(22,9)\end{array}$ & $\begin{array}{c}545 \\
(72,76)\end{array}$ & $\begin{array}{c}108 \\
(77,1)\end{array}$ \\
\hline Muar & $\begin{array}{c}- \\
(0)\end{array}$ & $\begin{array}{c}- \\
(0)\end{array}$ & $\begin{array}{c}16 \\
(21,9)\end{array}$ & $\begin{array}{c}- \\
\text { (0) }\end{array}$ & $\begin{array}{c}57 \\
(78,1)\end{array}$ & $\begin{array}{c}5 \\
(100)\end{array}$ \\
\hline Asinina & $\begin{array}{c}- \\
(0)\end{array}$ & $\begin{array}{c}- \\
(0)\end{array}$ & $\begin{array}{c}1 \\
(25)\end{array}$ & $\begin{array}{c}- \\
(0)\end{array}$ & $\begin{array}{c}3 \\
(75) \\
\end{array}$ & $\begin{array}{c}- \\
(0)\end{array}$ \\
\hline Total & $\begin{array}{c}2 \\
(0,24) \\
\end{array}$ & $\begin{array}{l}- \\
(0)\end{array}$ & $\begin{array}{c}219 \\
(26,51)\end{array}$ & $\begin{array}{c}32 \\
(22,1)\end{array}$ & $\begin{array}{c}605 \\
(73,25) \\
\end{array}$ & $\begin{array}{c}113 \\
(77,9)\end{array}$ \\
\hline
\end{tabular}

\section{Discussão e Conclusões}

Os valores encontrados estão bem próximos aos relatados em Rondônia por Aguiar et al. ${ }^{10}$ de 22,7\%, no Paraná por Lara et al. ${ }^{11}$ com $14,3 \%$ e no Pará por Heinemann et al. ${ }^{12}$ que encontraram $17 \%$ de soropositivos. Os valores obtidos neste trabalho foram menores do que os valores observados no Estado de São Paulo por Cunha et al. ${ }^{13}$ e Lara et al. ${ }^{14}$ de 27,2\% e $33,4 \%$, respectivamente. Por outro lado, a ocorrência dos HVE detectada nesta pesquisa foi maior do que a observada por Diel et al. ${ }^{15}$ de $4,5 \%$ no Rio Grande do Sul.
A ocorrência relativamente baixa pode ser atribuída às características epidemiológicas dos animais testados, pois elas foram provenientes de animais hígidos assintomáticos, sendo que a soropositividade para HVE é um indicativo de infecção latente ${ }^{15}$.

Além disso, com os resultados obtidos na presente pesquisa, como pode ser observado na tabela 1 , o HVE encontra-se amplamente disseminado no Estado de Minas Gerais, pois todas as regiões estudadas apresentaram animais sororreagentes.

A confirmação da presença de anticorpos anti-HVE no Estado de Minas Gerais nesse primeiro relato de 
literatura deve ser considerada como fator epidemiológico importante, pois o HVE é responsável por prejuízos econômicos significativos em locais onde a infecção é endêmica e em regiões onde a equideocultura é economicamente relevante.

No presente trabalho, a maioria dos animais positivos $(77,9 \%)$ encontrava-se acima da faixa de quatro anos (Tabela 3) provavelmente em função do maior tempo de exposição destes animais aos HVE de modo semelhante ao descrito por Nordengrahn et al. ${ }^{16}$.

Esses animais adultos são as principais fontes de infecção para os potros na transmissão do HVE na população de equídeos ${ }^{17}$.

\section{Referências}

1.ALLEN, G. P.; BRYANS, J. T. Molecular epizootiology, pathogenesis, and prophylaxis of equine herpesvirus-1 infectious. In: PANDEY, R. Progress in veterinary microbiology and immunology: veterinary microbiology. Basel: D. Karger, 1986. p. 78-144.

2.NUGENT, J.; BURCH-MACHIN, I.; SMITH, K. C. MUMFORD, J. A.; SWANN, Z.; NEWTON, J. R.; BOWDEN, R. J.; ALLEN, G. P.; DAVIS-POYNTER, N. Analysis of equid herpesvirus 1 strain variation reveals a point mutation of the DNA polymerase strongly associated with neuropathogenic versus nonneuropathogenic disease outbreaks. Journal of Virology, v. 80, n. 8, p. 4047-4060, 2006.

3.LARA, M. C. C. S. H.; CUNHA, E. M. S.; VILLALOBOS, E. M. C.; NASSAR, A. F. C.; ASANO, K. M.; FERNANDES, W. R.; RICHTZENHAIN, L. J.; BRANDÃO, P. E.; MORI, E. Isolation of Equid Herpesvirus Type 1 associated with neurological disease in horses: a case report in Brazil. Arquivos do Instituto Biológico, v. 75, n. 2, p. 221-224, 2008.

4.REINER, U. R.; DE LUCCA NETO, D.; NILSSON, M. R.; NILSSON, T. T.; KOTAIT, I. Isolamento do vírus do aborto equino em Campinas, Estado de São Paulo. In: CONGRESSO BRASILEIRO DE MEDICINA VETERINÁRIA, 13., 1972, Brasília. Anais... Brasília: Sociedade Brasileira de Medicina Veterinária, 1972. p. 283-284.

5.CUNHA, E. M. S.; PEIXOTO, Z. M. P.; KROEFF, S. S.; QUEIROZ, L. H.; KOTAIT, I. Isolamento e identificação do herpesvírus equino tipo 1 (EHV-1): confirmação do diagnóstico clínico. In: REUNIÃO ANUAL DO INSTITUTO BIOLÓGICO (RAIB), 6., 1993, São Paulo. Anais... São Paulo: RAIB, 1993. p. 15.

6. WEIBLEN, R.; RABUSKE, M.; REBELATTO, M. C.; NOBRE, V. M. T.; CANABARRO, T. F. Abortion due to equine herpesvirus in southern Brazil. Brazilian Journal of Medical and Biological Research, v. 27, p. 1317-1320, 1994.

7.CARVALHO, R.; OLIVEIRA, A. M.; SOUZA, A. M.; PASSOS, L. M. F; MARTINS, A. S. Prevalence of equine herpesvirus type 1 latency detected by polymerase chain reaction. Archives
Não houve diferença entre os sexos na análise comparativa (19,5\% nos machos e $17,47 \%$ nas fêmeas) (Tabela 2), de modo semelhante aos resultados apresentados por Moreira, Weiss e Kruger ${ }^{18}$.

Apesar da reduzida população de asininos e muares utilizados no presente estudo, pode-se sugerir que esses animais apresentaram menor ocorrência de anticorpos anti-HVE quando comparados à população de cavalos. No entanto, Ataseven et al. ${ }^{19}$ destacaram a importância dos asininos e muares como potenciais fontes de infecção para as populações de equinos, já que essas espécies geralmente convivem juntas.

of Virology, v. 145, n. 9, p. 1773-1787, 2000.

8.CARVALHO, R. F.; CUNHA, E. M. S.; CARON, L.; DOMINGUES, H. G.; D'ARCE, R. C. F.; COSWIG, L. T.; ALMEIDA, R. S.; ARNS, C. W. A new brazilian isolate of the abortogenic equine vírus (equine herpesvirus type 1). Virus Reviews Research, v. 9, p. 79, 2004. Supplement 1. Trabalho apresentado no XVI Encontro Nacional de Virologia.

9. KOTAIT, I.; PEIXOTO, Z. M. P.; QUEIROZ, L. H.; CUNHA, E. M. S.; SOUZA, M. C. A. M.; MACRUZ, R.; FREITAS, C. A. Diagnóstico laboratorial do aborto equino a vírus através de imunofluorescência e soroneutralização. Revista de Microbiologia, v. 20, n. 1, p. 128-132, 1989.

10.AGUIAR, D. M.; CAVALCANTE, G. T.; LARA, M. C. C. S. H.; VILLALOBOS, E. M. C.; CUNHA, E. M. S.; OKUDA, L. H.; STEFANO, E.; NASSAR, A. F. C.; SOUZA, G. O.; VASCONCELLOS, S. A.; LABRUNA, M. B.; CAMARGO, L. M. A.; GENNARI, S. M. Prevalência de anticorpos contra agentes virais e bacterianos em equídeos do município de Monte Negro, Rondônia. Amazônia Ocidental Brasileira. Brazilian Journal Veterinary Research Animal Science, v. 45 , n. 4 , p. $269-276,2008$

11.LARA, M. C. C. S. H.; BARROS FILHO, I.; VIANA, F.; GREGORY, L.; CUNHA, E. M. S.; CASTRO A. F.; BIRGEL, E. H.; FERNANDES, W. R. Pesquisa de anticorpos contra o vírus da arterite dos equinos (VAE) e herpes equino tipo 1 (HVE-1) em cavalos criados em Curitiba, PR. A Hora Veterinária, v. 23 n. 135, p. 26-28, 2003.

12.HEINEMANN, M. B.; CORTEZ, A.; SOUZA, M. C. C. GOTTI, T.; FERREIRA, F.; HOMEM, V. S. F.; FERREIRA NETO, J. S.; SOARES, R. M.; SAKAMOTO, S. M.; CUNHA, E. M. S.; RICHTZENHAIN, L. J. Soroprevalência da anemia infecciosa equina, da arterite viral dos equinos e do aborto equino a vírus no município de Uruará, PA, Brasil. Brazilian Journal of Veterinary Research and Animal Science, v. 39, n. 1, p. $50-53,2002$.

13. CUNHA, E. M. S.; FERRARI, C. I. L., LARA, M. C. C. S. H.; SILVA, L. H. Q. Presença de anticorpos contra o herpesvírus 
equino 1 (HVE-1) em equinos do noroeste do Estado de São Paulo. Arquivos do Instituto Biológico, v. 69, n. 1, p. 1-5, 2002.

14.LARA, M. C. C. S. H.; CUNHA, E. M. S.; NASSAR, A. F. C.; GREGORY, L.; BIRGEL, E. H.; FERNANDES, W. R. Ocorrência do herpesvírus equino 1 (HVE-1) em cavalos criados no Estado de São Paulo, Brasil. Ars Veterinária, v. 19, n. 3, p. 254-259, 2003.

15.DIEL, D. G.; ALMEIDA, S. R.; WEIBLEN, R.; FRANDOLOSO, R.; ANZILIERO, D.; KREUTZ, L. C.; GROFF, F. H. S.; FLORES, E. F. Prevalência de anticorpos contra os vírus da influenza, da arterite viral e herpesvírus em equinos do Estado do Rio Grande do Sul, Brasil. Ciência Rural, Santa Maria, v. 36, n. 5, p. 1467-1473, 2006.

16.NORDENGRAHN, A.; MERZA, M.; SVEDLUND, G.; RONEUS, M.; BERNDTSSON, T.; LINDHOLM, A.; RUMMER, H. E.; STUDDERT, M. J.; ABUSUGRA, I.; GUNNARSSON, E.; KLINGEBORN, B. A field study of the application of a type-specific test distinguishing antibodies to equine herpesvirus-4 and -1. In: EQUINE INFECTIOUS DISEASE, 8., 1999, Dubai. Anais... Dubai: Newmarket: R\&W Publications, 1999. p. 125-128.

17.GILKERSON, J. R.; WHALLEY, J. M.; DRUMMER, H. E.; STUDDERT, M. J.; LOVE, D. N. Epidemiology of EHV-1 and EHV-4 in the mare and foal populations on a Hunter Valley stud farm: are mares the source of EHV-1 for unweaned foals. Veterinary Microbiology, v. 68, p. 27-34, 1999.

18. MOREIRA, N.; WEISS, R. R.; KRUGER, E. R. Frequência de anticorpos neutralizantes contra o herpesvírus equino tipo 1 . Scientia Agrária, v. 1, n. 1-2, p. 9-14, 2000.

19.ATASEVEN, V. S.; DAGALP, S. B.; GUZEL, M.; BASARAN, Z.; TAN, M. T.; GERAGHTY, B. Prevalence of equine herpesvirus- 1 and equine herpesvirus- 4 infections in equidae species in Turkey as determined by ELISA and multiplex nested PCR. Research Veterinary Science, v. 86, n. 2, p. 339344, 2008. 